\title{
No evidence of early head circumference enlargements in children later diagnosed with autism in Israel
}

\author{
Ilan Dinstein ${ }^{1,2^{*}}$, Shlomi Haar ${ }^{2}$, Shir Atsmon ${ }^{2}$ and Hen Schtaerman ${ }^{3}$
}

\begin{abstract}
Background: Large controversy exists regarding the potential existence and clinical significance of larger brain volumes in toddlers who later develop autism. Assessing this relationship is important for determining the clinical utility of early head circumference $(H C)$ measures and for assessing the validity of the early overgrowth hypothesis of autism, which suggests that early accelerated brain development may be a hallmark of the disorder.

Methods: We performed a retrospective comparison of $\mathrm{HC}$, height, and weight measurements between 66 toddlers who were later diagnosed with autism and 66 matched controls. These toddlers represent an unbiased regional sample from a single health service provider in the southern district of Israel. On average, participating toddlers had $>8$ measurements between birth and the age of two, which enabled us to characterize individual HC, height, and weight development with high precision and fit a negative exponential growth model to the data of each toddler with exceptional accuracy.

Results: The analyses revealed that HC sizes and growth rates were not significantly larger in toddlers with autism even when stratifying the autism group based on verbal capabilities at the time of diagnosis. In addition, there were no significant correlations between ADOS scores at the time of diagnosis and $\mathrm{HC}$ at any time-point during the first 2 years of life.

Conclusions: These negative results add to accumulating evidence, which suggest that brain volume is not necessarily larger in toddlers who develop autism. We believe that conflicting results reported in other studies are due to small sample sizes, use of misleading population norms, changes in the clinical definition of autism over time, and/or inclusion of individuals with syndromic autism. While abnormally large brains may be evident in some individuals with autism and more clearly visible in MRI scans, converging evidence from this and other studies suggests that enlarged HC is not a common etiology of the entire autism population. Early HC measures, therefore, offer very limited clinical utility for assessment of autism risk in the general population.
\end{abstract}

Keywords: Autism, Head circumference, Biomarker, Early detection, Neuroanatomy

\section{Background}

Early brain overgrowth is one of the most prominent contemporary theories of autism development [1-3]. According to the theory, autism may be caused by different genetic predispositions and/or environmental insults that accelerate cellular proliferation, migration, differentiation, and development so as to generate abnormally

\footnotetext{
* Correspondence: dinshi@bgu.ac.il

${ }^{1}$ Psychology Department, Ben Gurion University, Beer Sheva 84105, Israel

${ }^{2}$ Cognitive and Brain Sciences Department, Ben Gurion University, Beer Sheva 84105, Israel

Full list of author information is available at the end of the article
}

large brains during the first 2 years of life. Early accelerated growth is thought to be followed by arrested growth, which explains why adolescents and adults with autism do not have larger brain volumes [4]. Nevertheless, the availability of head circumference $(\mathrm{HC})$ as a biomarker during early development could be extremely useful for identifying toddlers at risk of developing autism even before the onset of behavioral symptoms [2]. Since $\mathrm{HC}$ is an excellent correlate of brain volume during the first years of life [5], testing whether toddlers 
with autism indeed exhibit early brain overgrowth is a relatively straight forward venture.

Previous studies have reported that toddlers who later develop autism are born with normal $\mathrm{HC}$ and then develop abnormally large $\mathrm{HC}$ during the first 2 years of life [6-10]. These findings have been corroborated by post mortem [11] and MRI [12-16] studies that have reported significantly larger brains in toddlers who develop autism. Later studies, however, have questioned whether early overgrowth is specific to the brain or reflects general body overgrowth as apparent also in height and weight measurements [17]. Furthermore, the validity of early findings that were mostly based on comparisons with CDC population norms have been questioned, because these norms have underestimated the true $\mathrm{HC}$ distribution in the general population [18]. With this in mind, several comparisons of early $\mathrm{HC}$ measurements between toddlers with autism and community-matched controls did not find any significant between-group differences [19-23]. These studies demonstrate the ongoing controversy regarding the existence and clinical significance of early brain overgrowth in toddlers with autism.

When interpreting the studies above, it is important to consider the sample characteristics in each case. For example, it has been suggested that larger brain volumes may be more strongly associated with specific autism etiologies involving regression [24], immunological insults [25], and specific genetic abnormalities (e.g., PTEN mutations [26]). Furthermore, HC is hereditary regardless of autism [27]. Differences in genetics and the environmental exposures of the examined sample as well as the inclusion/exclusion criteria of each study may, therefore, have an impact on potential differences across autism and control groups. For example, contrary to previous reports from the USA [28], assessment of large clinical databases in Norway and Israel reported modest [22] or no [29] differences in the rates of macrocephaly $(\mathrm{HC}>97 \%$ of the general population) in children diagnosed with autism.

To further address these issues, we performed a retrospective assessment of $\mathrm{HC}$ measurements that were recorded at birth and between the ages of 1-24 months at Maccabi Healthcare infant wellness centers in the southern district of Israel. The collected data included, on average, $>8 \mathrm{HC}$, weight, and height measurements from each of the 66 toddlers who were later diagnosed with idiopathic autism and the 66 community-matched controls. This data contained approximately twice as many samples per toddler in comparison to previous studies. The large number of samples enabled us to examine the longitudinal $\mathrm{HC}$ development of individual toddlers with high temporal resolution and fit a negative exponential growth model to the data of each toddler with remarkable accuracy. In addition, we examined the potential relationship between early $\mathrm{HC}$ measures and autism severity measures at the time of diagnosis as assessed by the Autism Diagnostic Observation Schedule (ADOS; [30]). Importantly, the examined data represents an unbiased community sample of the members of Maccabi Healthcare services who make up approximately one third of the population in southern Israel.

\section{Methods}

\section{Participants}

We collected retrospective $\mathrm{HC}$, weight, and height data from electronic patient records of children who were diagnosed with autism at the Maccabi Child Development Center in Beer Sheva ( $n=66,60$ boys). The autism group included 22 children who were diagnosed according to DSM-IV criteria (17 with autism, 4 with PDDNOS, and 1 with Asperger's syndrome) and 44 children who were diagnosed according to DSM-V criteria and received a formal diagnosis of autism spectrum disorders (ASD). Diagnosis was confirmed in the first group of 22 children using the first [30] edition of the ADOS and in the later 44 children using the second [31] edition of the ADOS. The mean age of diagnosis was 36.94 months (standard deviation 13 months). Each child with autism was matched, in terms of gender and date of birth $( \pm 30$ days), with a typically developing control child from the same southern Maccabi Healthcare district (Table 1). Children with known chromosomal disorders, known genetic disorders (e.g., RETT), hydrocephalus, additional developmental and neurological disorders, and those born before 36 weeks of gestation or below $2 \mathrm{~kg}$ were excluded from the study.

\section{Head circumference, weight, and height data}

We extracted all of the available $\mathrm{HC}$, weight, and height measurements from the electronic patient records of each child. All of the measurements were performed by nurses at Maccabi Healthcare Infant Wellness Centers, except for the measurement at birth, which was conducted by a midwife. Both the nurses and the midwives

Table 1 Sample characteristics including the number of toddlers (relative number of females), the term in weeks, ADOS and $\mathrm{ADI}$ scores, age at diagnosis, and number of $\mathrm{HC}$ samples available from the individual patient records

\begin{tabular}{lll}
\hline & Autism & Control \\
\hline Number of toddlers (females) & $66(6)$ & $66(6)$ \\
Term in weeks (range) & $39.1(36-42)$ & $39.5(36.2-41.5)$ \\
ADOS total (range) & $16.1(7-26)$ & \\
ADOS severity score (range) & $7(4-10)$ & \\
ADI-R (range) & $18(7-26)$ & \\
Age at diagnosis (range) & $3(1-5.3)$ years & \\
Number of HC samples & $8.3(4-12)$ & $8.4(4-12)$
\end{tabular}

Range of the sample is in parentheses 
perform dozens of $\mathrm{HC}$, weight, and height measurements every week and are extremely proficient in this work. The mean number of measurements per toddler was 8.3 (SD 2.1) in the ASD group and 8.42 (SD 1.74) in the control group (range 4-12 samples per child in both groups). There were no significant differences in the number of measurements across ASD and control groups ( $t(125)=-0.48, p=0.6$, two-tailed $t$ test). In Israel, all children are invited to visit a baby clinic at the ages of $1,2,4,6,9,12,15,18$, and 24 months to complete standard check-ups and immunizations as part of the free social health care services. The final number of visits/measurements and the precise age of the visits, however, depend on parental compliance.

\section{Data analyses}

Analyses were performed with custom written code in Matlab (Mathworks Inc., USA). Since each child had measurements at different time-points within the first 24 months of life, we first linearly interpolated the measurements into vectors with a time resolution of weeks using the interp1 function in Matlab. This enabled us to estimate the week-by-week $\mathrm{HC}$, weight, and height values of each child from the age of their first measurement to the age of their last measurement without assuming an overall growth model with a predefined shape (Fig. 1). We then compared HC, weight, and height of children who later developed autism and controls while binning the data into 3-month intervals from birth to the age of 24 months. We used two-tailed two-sample $t$ tests with unequal variances to assess the significance of differences across groups. We also computed the Pearson's correlation coefficient between ADOS severity scores (see below) and $\mathrm{HC}$ measurements for each of the age intervals (bins) described above. The significance of the correlation coefficients was not corrected for multiple comparisons in order to increase sensitivity.

ADOS calibrated severity scores (also known as "Comparison Score") were calculated using the ADOS-2 algorithm [31] in children who were diagnosed by the ADOS-2 $(n=44)$ or an alternative algorithm [32] available for children who were diagnosed with the first version of $\operatorname{ADOS}(n=22)$.

We used a negative exponential growth model (Matlab code is available in the Additional file 1) that was used in previous $\mathrm{HC}$ studies of autism [19] to estimate the rate of $\mathrm{HC}$ growth in each toddler during the first 2 years of life:

$$
\mathrm{HC}=\alpha+(\beta-\alpha) * e^{-\gamma * x}
$$

The model describes a nonlinear function where $\alpha$ represents the asymptote (a maximum size for growth within the time frame considered), $\beta$ represents the intercept at age 0 (i.e., birth), and $\gamma$ represents the anti$\log$ of the rate of change (growth rate from birth to the asymptote). The three parameters were estimated for each of the toddlers. We used the same model to examine weight and height growth as well. We tested for group differences by performing two-tailed $t$ tests with unequal variances for each of the model parameters. The significance of differences across groups was not corrected for multiple comparisons in order to increase sensitivity.
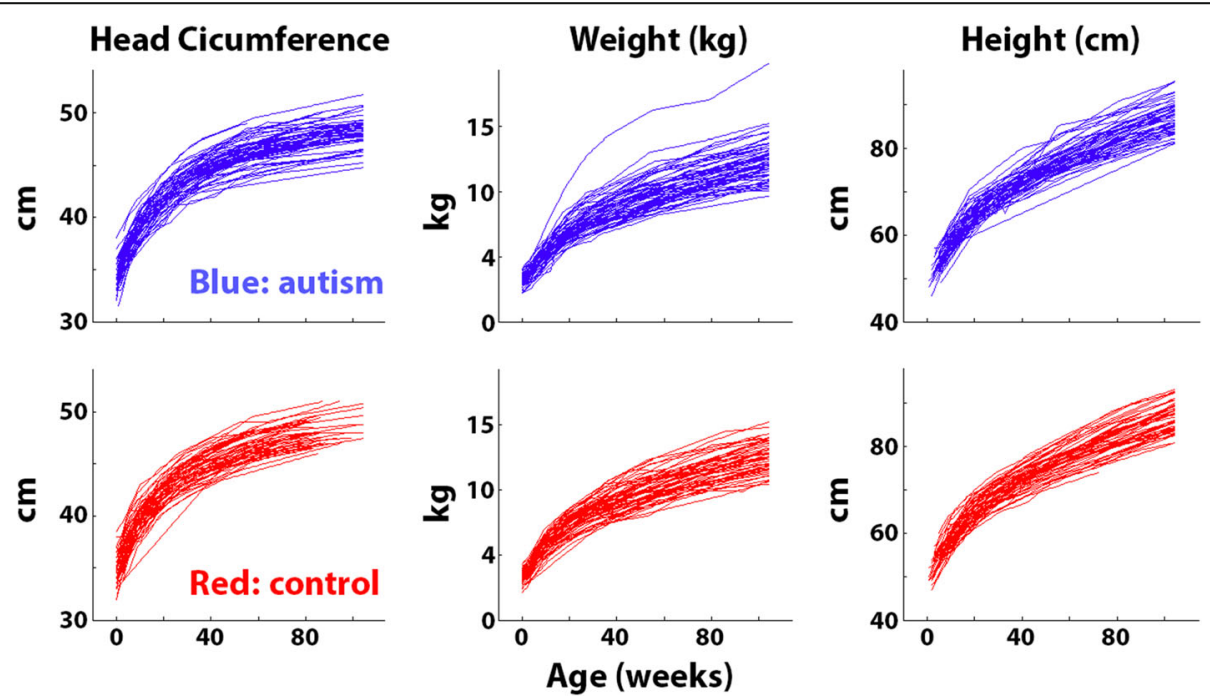

Fig. 1 Head circumference, weight, and height measurements from the 66 toddlers who later developed autism (blue) and the 66 matched controls (red). Each line represents the development of a single toddler as estimated with linear interpolation between measurement points (see "Methods") 


\section{Results}

Individual development curves

On average, there were $>8 \mathrm{HC}$, height, and weight measurements available for each toddler in our sample. The precise number of measurements and their relative timing (i.e., toddler's age at each measurement), however, varied across toddlers. To overcome these differences across toddlers, we performed a linear interpolation over time, connecting pairs of datapoints with straight lines. In this manner, we built a growth curve for each toddler with a temporal resolution of weeks (Fig. 1). This enabled us to examine the developmental changes in $\mathrm{HC}$, weight, and height of individual toddlers from each of the groups throughout their first 2 years of life. All three measures exhibited the typical logarithmic shape, and the distribution of individual values was qualitatively similar across the two groups (Fig. 1). Note the highresolution of these linearly interpolated growth curves, which is a feature of the large number of samples obtained from each toddler (see "Methods").

\section{Comparisons across autism and control groups}

Mean growth curves of the two groups were overlapping for all three measures (Fig. 2, top row). We tested whether there were any differences across groups at multiple ages between birth and 24 months in 3-month intervals. Note that height is not measured at birth in Israel; hence, comparisons of this measure start from the age of 3 months. The control group exhibited significantly larger head circumference and weight at birth and at 3 months of age $(p<0.05, t>2.1$, uncorrected to increase sensitivity, Fig. 2, bottom row). All other between-group comparisons did not reveal any statistically significant differences across groups (see Table 2). Note that with 66 toddlers in each group, our sample size yields a power of 0.88 for detecting larger $\mathrm{HC}$ measures in the autism group (assuming an effect size of 0.5 ).

\section{Comparison of growth model parameters}

We fit a nonlinear growth model (see "Methods"), which contained three parameters: intercept, rate of change, and asymptote, to the data of each toddler (Fig. 3). In agreement with the results described above, control toddlers exhibited significantly larger intercept $(\beta)$ values when modeling $\mathrm{HC}(p=0.02, t=2.3$, Fig. $3 \mathrm{~b})$ or weight $(p=0.007, t=2.8$, Fig. 3c) measures. The significant difference in the intercept indicates that $\mathrm{HC}$ and weight measures were significantly larger in control toddlers at birth. The two other parameters did not differ across groups for any of the measures. The lack of difference in rate of change indicates that there were no significant growth rate differences between autism and control toddlers in any of the measures. Note that the model fit the data of individual toddlers extremely well, explaining $>94 \%$ of the variance in all cases, for all three measures ( $R^{2}$ values in Fig. 3 ).

Performing the same analysis only with male toddlers produced equivalent results: control toddlers exhibited significantly larger intercept $(\beta)$ values when modeling $\mathrm{HC}$
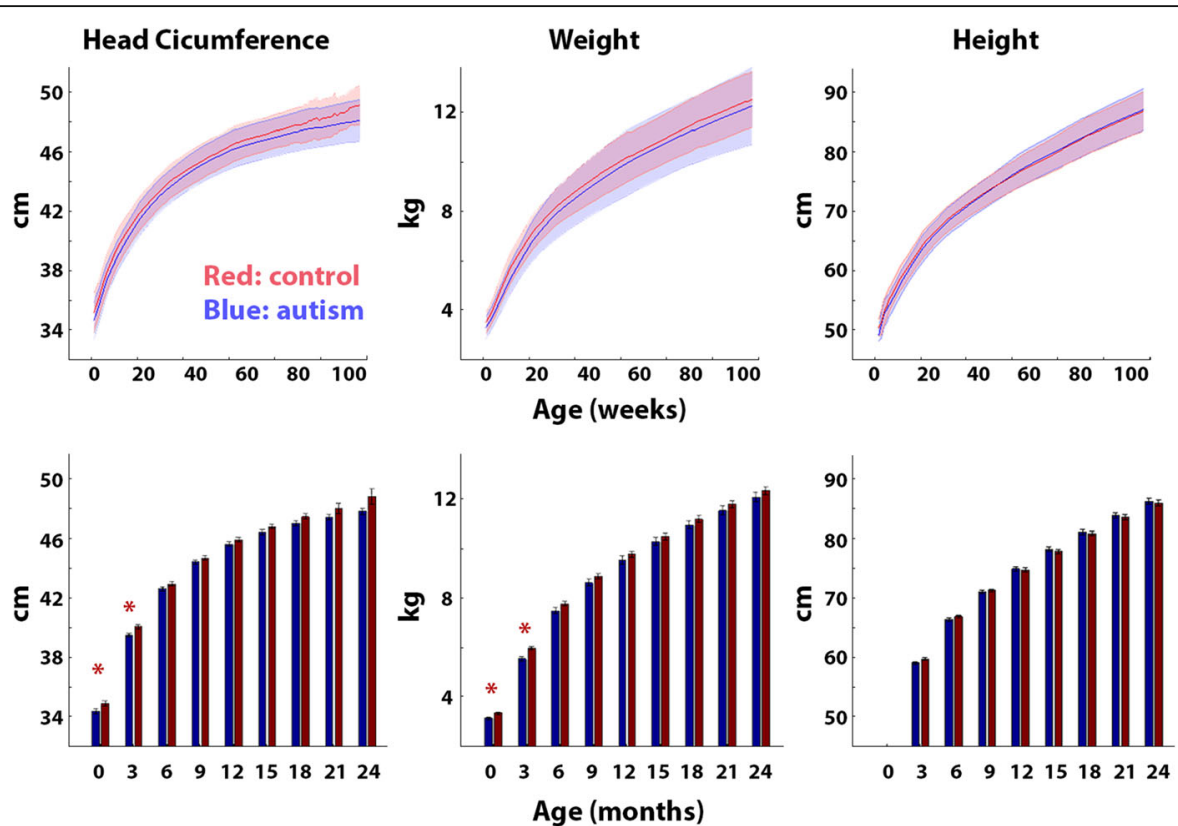

Fig. 2 Comparison of HC, weight, and height across autism (blue) and control (red) groups. Top row: Mean of each group as a function of age in weeks. Shaded area: standard deviation across toddlers. Bottom row: Mean of each group in 3-month periods. Error bars: standard error of the mean across subjects. Red asterisks: significantly larger values in the control group $(p<0.05$, uncorrected to increase sensitivity) 
Table 2 Comparisons of HC, weight, and height across groups from birth to the age of 24 months in 3-month intervals

\begin{tabular}{|c|c|c|c|c|c|}
\hline \multicolumn{6}{|c|}{ Head circumference } \\
\hline Age & Autism & Control & Autism-control & $t$ value & $p$ value \\
\hline Birth & 34.4 & 35 & -0.6 & -2.1 & $0.04^{*}$ \\
\hline 3 months & 39.7 & 40.2 & -0.5 & -2.8 & $0.006^{*}$ \\
\hline 6 months & 42.8 & 43.2 & -0.4 & -1.7 & 0.1 \\
\hline 9 months & 44.7 & 44.9 & -0.2 & -1.3 & 0.19 \\
\hline 12 months & 45.9 & 46.2 & -0.3 & -1.3 & 0.21 \\
\hline 15 months & 46.7 & 47.1 & -0.4 & -1.7 & 0.1 \\
\hline 18 months & 47.2 & 47.7 & -0.5 & -1.9 & 0.06 \\
\hline 21 months & 47.7 & 48.3 & -0.6 & -1.4 & 0.17 \\
\hline 24 months & 48.1 & 49.1 & -1 & -1.8 & 0.12 \\
\hline \multicolumn{6}{|l|}{ Weight } \\
\hline Age & Autism & Control & Autism-control & $t$ value & $p$ value \\
\hline Birth & 3.2 & 3.4 & -0.2 & -2.7 & $0.007^{*}$ \\
\hline 3 months & 5.6 & 6.1 & -0.5 & -3.8 & $0.0004^{*}$ \\
\hline 6 months & 7.6 & 7.9 & -0.3 & -1.9 & 0.06 \\
\hline 9 months & 8.7 & 9 & -0.3 & -1.4 & 0.1 \\
\hline 12 months & 9.7 & 9.9 & -0.2 & -1.2 & 0.24 \\
\hline 15 months & 10.4 & 10.6 & -0.2 & -0.9 & 0.36 \\
\hline 18 months & 11.1 & 11.3 & -0.2 & -1 & 0.31 \\
\hline 21 months & 11.7 & 12 & -0.3 & -1.1 & 0.28 \\
\hline 24 months & 12.3 & 12.5 & -0.2 & -1 & 0.31 \\
\hline \multicolumn{6}{|l|}{ Height } \\
\hline Age & Autism & Control & Autism-control & $t$ value & $p$ value \\
\hline 3 months & 59.4 & 60 & -0.6 & -1.9 & 0.06 \\
\hline 6 months & 66.9 & 67.3 & -0.4 & -1.2 & 0.24 \\
\hline 9 months & 71.5 & 71.8 & -0.3 & -1.4 & 0.58 \\
\hline 12 months & 75.5 & 75.3 & 0.2 & -1.2 & 0.73 \\
\hline 15 months & 78.8 & 78.5 & 0.3 & -0.9 & 0.53 \\
\hline 18 months & 81.7 & 81.5 & 0.2 & -1 & 0.72 \\
\hline 21 months & 84.5 & 84.2 & 0.3 & -1.1 & 0.63 \\
\hline 24 months & 87 & 86.7 & 0.3 & -1 & 0.67 \\
\hline
\end{tabular}

$\mathrm{HC}$ and height are in centimeters and weight is in kilograms. Columns: mean of the autism group, mean of the control group, the difference between autism and control groups, $t$ values, and $p$ values from a two-tailed twosample $t$ test with unequal variance. $p$ values are not corrected to increase sensitivity Asterisks: $p$ value $<0.05$

$(p=0.03, t=2.2)$ or weight measures $(p=0.01, t=2.5)$, and there were no significant differences across groups in the rate of change and asymptote parameters.

\section{Head circumference and autism severity}

We examined the potential relationships between $\mathrm{HC}$ as measured at specific ages and autism severity as quantified by the ADOS total score or calibrated severity score (see "Methods") at the time of diagnosis. All of the correlations were weak and not statistically significant indicating that $\mathrm{HC}$ measures were not associated with ADOS scores (Fig. 4).

\section{Verbal and nonverbal toddlers}

We performed the same HC comparisons described above (Fig. 2), while separating nonverbal toddlers who were diagnosed with the toddler module $(n=14)$ or module $1(n=36)$ of the ADOS from the verbal toddlers who were diagnosed with module $2(n=15)$ of the ADOS. Significantly larger HC was apparent in the control group at 3 months of age in comparison to the autism toddlers diagnosed with module $1(p=0.008, t=2.7$, two-tailed $t$ test, uncorrected to increase sensitivity) and at 24 months of age in comparison to the autism toddlers diagnosed with module $2(p<0.04, t>2.4$, twotailed $t$ test, uncorrected to increase sensitivity). All other differences between autism and control groups were not significant (Fig. 5). This indicates that early HC measures are not larger in children who later develop autism regardless of their verbal abilities at time of diagnosis.

\section{Discussion}

Our results demonstrate that toddlers diagnosed with autism in southern Israel do not exhibit early $\mathrm{HC}$ overgrowth during the first 2 years of life. Comparisons with control toddlers who were born at equivalent times and geographical locations revealed that $\mathrm{HC}$, weight, and height measurements were mostly indistinguishable from those of toddlers with autism during the first 24 months of development and, if anything, were larger in the control group at birth and 3 months of age (Figs. 1 and 2). Furthermore, growth parameters estimated using a nonlinear negative exponential model were not significantly different across groups except for the intercept parameter, which indicated significantly larger $\mathrm{HC}$ and weight measures in the control group at birth (Fig. 3). Equivalent findings were evident when examining only male toddlers and when splitting toddlers with autism into verbal and nonverbal groups according to the ADOS modules used for diagnosis (Fig. 5). Finally, HC during the first 24 months of development did not predict later autism severity at the time of diagnosis (Fig. 4).

An important strength of the current study lies in the relatively large number of measurements that were extracted from each of our 132 participants. While most previous studies relied on 3-4 HC samples per child, we extracted $>8 \mathrm{HC}$, weight, and height measurements per toddler, on average. This enabled us to estimate $\mathrm{HC}$, weight, and height growth rates with exceptional accuracy as reflected in the goodness-of-fits of individual toddlers ( $>94 \%$ of the variance explained in all toddlers, Fig. 3). Furthermore, each of the 66 toddlers with autism was closely matched to a control toddler who was born 

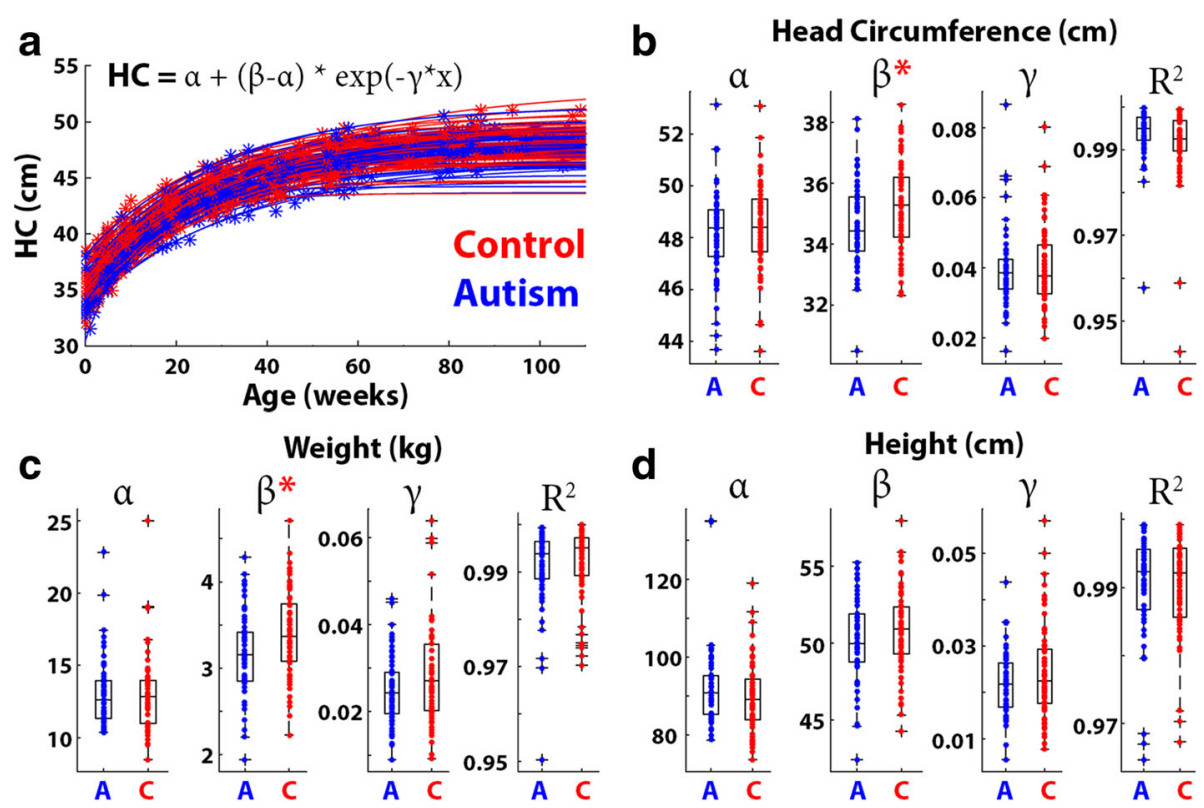

Fig. 3 Comparison of head growth modeling parameters across autism (blue) and control (red) groups. Demonstration of HC growth model fits in individual toddlers: asterisks represent measurements and the lines represent the model fits (a). Boxplots demonstrating the HC (b), weight (c), and height (d) growth parameters: asymptote $(\alpha)$, intercept $(\beta)$, and rate of change $(\gamma)$ in each group. Red asterisks: significantly larger parameter values in the control group. $R^{2}$ : box plots demonstrating the model fits of individual toddlers in each group for each of the measures

within 30 days in the same geographical location. This ensured that the examined $\mathrm{HC}$, weight, and height measurements were collected by similarly trained clinical staff within the same local community. Hence, the growth rates presented in the current study are likely to represent the true distribution of rates in the autism and control populations of southern Israel.

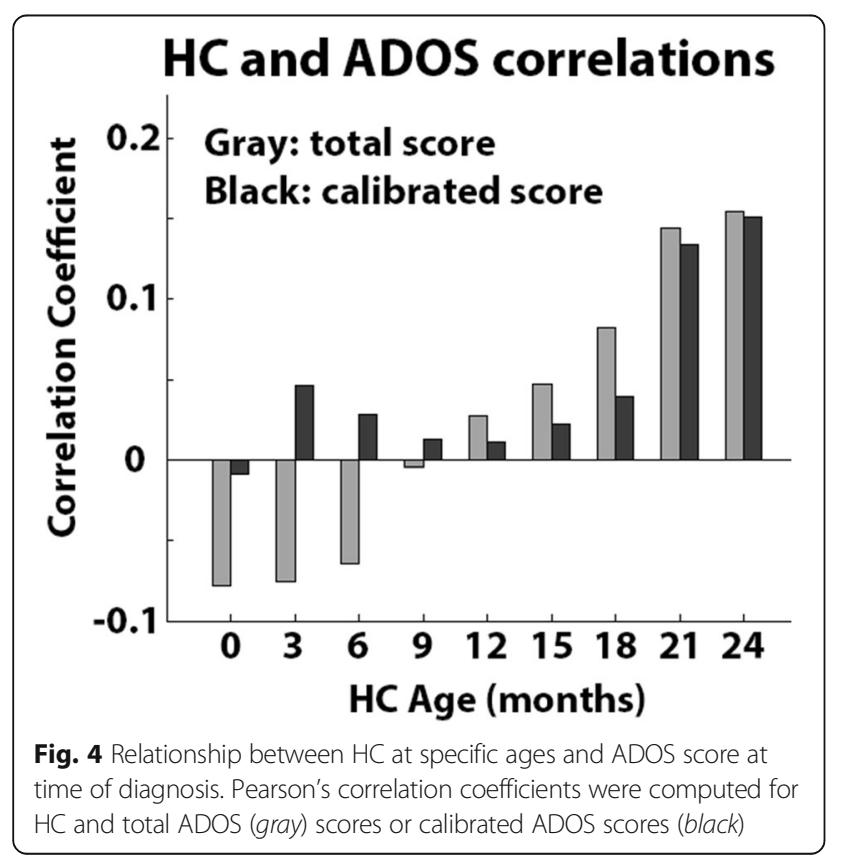

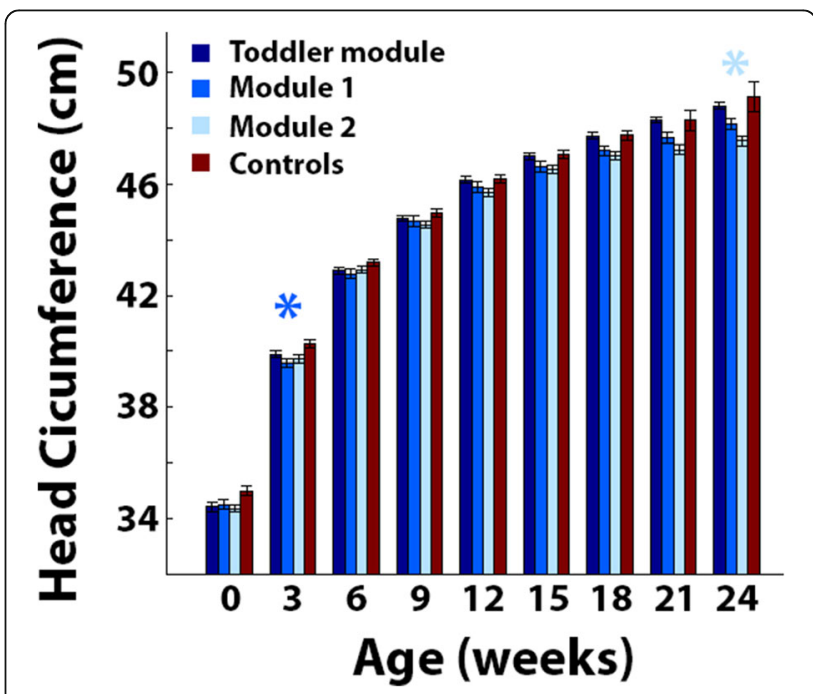

Fig. 5 Comparison of $\mathrm{HC}$ at specific ages when separating the autism group according to ADOS modules. Mean HC in toddlers with autism diagnosed with the toddler module (dark blue), module 1 (medium blue), or module 2 (light blue), and control toddlers (red). Error bars: standard error of the mean across toddlers in each group. Asterisks: significantly larger $\mathrm{HC}$ in the control group as compared with that in the autism group of the corresponding color $(p<0.05$, uncorrected to increase sensitivity) 


\section{HC overgrowth in autism}

Previous studies have reported that $\mathrm{HC}$ is enlarged in autism during the first 2 years of life $[6-10,12,17]$. Analogous studies have reported significantly higher rates of macrocephaly ( $\mathrm{HC}>97 \%$ of the general population) in children with autism [33-35]. While many of the $\mathrm{HC}$ and macrocephaly studies described above were biased by the use of misleading population norms published by the CDC [18], some studies have reported significantly larger $\mathrm{HC}$ in autism, even in comparisons with control toddlers from the same community [12, 17]. This evidence is often cited in support of the prominent early overgrowth theory of autism, which suggests that autism may be caused by abnormal cellular proliferation, migration, and differentiation that generate accelerated brain growth during the first 2 years of life [1-3].

In contrast to the studies described above, a growing body of literature has reported that $\mathrm{HC}$ measures during the first 2 years of life are not significantly larger in toddlers who later develop autism [19-23]. Similarly, recent assessments of large clinical databases in Norway and Israel have reported modest [22] or no [29] difference in macrocephaly rates between autism and control populations. Our results are in line with these later studies and present further evidence for a lack of difference across groups in both $\mathrm{HC}$ size and growth rate during the first 2 years of life.

We believe that the conflicting results between older studies that reported significant $\mathrm{HC}$ differences across groups and more recent studies that do not may be explained by several key reasons: First, many of the earlier studies compared $\mathrm{HC}$ measurements from toddlers with autism to outdated and misleading CDC norms that underestimated the true $\mathrm{HC}$ distribution of the general population in the USA [18]. Second, earlier studies, even if they included matched controls, were based on small samples of 20-30 individuals in each group while more recent studies and the current one were based on sample sizes that were at least twice as large. Given the large variability in $\mathrm{HC}$ across individuals of each group (Figs. 1 and 2), studies with larger samples are more likely to yield accurate estimates of the $\mathrm{HC}$ distributions in each group, which are necessary for assessing differences across groups [4]. Third, older studies may have included subjects with known genetic syndromes in comparison to more recent studies that exclude such individuals. Since syndromal subtypes of autism are specifically associated with macrocephaly (e.g., tuberous sclerosis [36] and PTEN mutations [26]), it is possible that some of the older studies may have included rare participants with extreme $\mathrm{HC}$ measures.

Another potential reason for conflicting findings across older and newer studies is the ongoing change in clinical criteria of autism diagnoses, which have led to a considerable increase in autism prevalence [37]. For example, recent samples of children with autism are likely to include children with milder forms of autism and/or higher cognitive function [38] as well as children who would have received a mental retardation diagnosis in the past [39]. While we did not find a relationship between early $\mathrm{HC}$ measures and autism severity at the age of diagnosis (Fig. 4), an older study did report such a relationship [9]. In addition, given the dramatic increase in autism prevalence, current samples of children with autism are likely to contain more biological heterogeneity and relatively fewer syndromic cases of autism.

\section{Environmental and genetic factors associated with $\mathrm{HC}$ growth}

HC growth rates are dependent on a wide variety of environmental and genetic factors, regardless of autism. For example, $\mathrm{HC}$ growth is associated with the richness of postnatal nutrition [40], pre-natal exposure to a variety of substances including folic acid [41] and acrylamide [42], and maternal stress levels during pregnancy [43]. Genetic risk factors include polymorphisms and mutations in a variety of genes such as PTEN and CHD8 [44]. Furthermore, $\mathrm{HC}$ is highly heritable regardless of autism and is highly correlated with genetic ancestry [27].

This means that the utility of early $\mathrm{HC}$ measures for clinical assessment of autism risk depends on whether findings are generalizable across multiple populations with distinct genetics and environmental exposures. The negative findings in this study and those of a recent macrocephaly study in the Israeli population [29] suggest that $\mathrm{HC}$ is, at the very least, a poor predictor of autism risk in the Israeli population. The equivalent negative results reported in studies from North America [19-21] and Europe [22], however, suggest that our findings are not due to genetic and/or environmental factors that are unique to Israel. A clearer understanding of how brain overgrowth differs in samples with distinct genetic and environmental factors is, therefore, critical for further evaluating the clinical utility of early $\mathrm{HC}$ measures in specific sub-groups of children with autism.

\section{The overgrowth hypothesis of autism}

$\mathrm{HC}$ is obviously a very coarse measure for testing the overgrowth hypothesis of autism. MRI scans offer far more detailed and accurate measures of total brain volume while enabling separation of gray and white matter volumes and assessment of cortical thickness and surface area. While such measures do not differ significantly between autism and control subjects who are over the age of six [4], toddlers with autism may exhibit larger brain volumes during the second year of life in comparison to controls [12-16]. Furthermore, specific overgrowth of cortical surface area may be apparent even during the 
first year of life in those who later develop autism [16]. Additional evidence from diffusion tensor imaging (DTI) studies suggests that toddlers with autism exhibit abnormal white matter microstructure, which may indicate early over-proliferation of neurons $[45,46]$ as also found in several post mortem studies [11, 47].

While specific neuroimaging measures of brain overgrowth may indeed differ between individuals with autism and controls during early development, converging evidence seems to suggest that $\mathrm{HC}$ measures do not capture these differences in a reliable manner during the first 2 years of life. This is unfortunate because neuroimaging studies are expensive and examine small samples that are usually biased (i.e., usually include parents who have the time, motivation, and capabilities to bring their children to the MRI center). In contrast, $\mathrm{HC}$ studies are cheaper and enable assessment of larger unbiased samples from the general population by examining $\mathrm{HMO}$ databases.

\section{Conclusions}

Given the large heterogeneity of mechanisms that have been implicated in the development of autism [48], it is not surprising that there are mixed reports regarding the existence of $\mathrm{HC}$ differences across autism and control groups in different studies/samples. Indeed, similarly conflicting reports exist with respect to many physiological and behavioral measures studied in individuals with autism [49]. The great challenge facing contemporary autism research is to define specific sub-groups of toddlers with autism who exhibit specific etiologies. While early brain overgrowth may embody one such etiology, it is likely to be relevant to particular syndromic forms of autism and to specific individuals who exhibit abnormally large brain volumes early in life. Future research regarding early overgrowth would, therefore, benefit from targeted studies with these particular individuals rather than attempting to associate early overgrowth with the entire autism population.

\section{Additional file}

Additional file 1: Matlab code for fitting the negative exponential growth model. (DOCX 15 kb)

\section{Acknowledgements}

We would like to thank the staff at the Maccabi Healthcare Child Development Center in Beer Sheva for their help with data collection.

\section{Funding}

This study was funded by the Israeli Science Foundation: Grant number 961/14 to ID and the German Israeli Foundation: Grant number I-2351201.2/2014 to ID.

\section{Availability of data and materials}

The data used in the study are available from the corresponding author on reasonable request.

\section{Authors' contributions}

SA collected the data and performed some of the data analysis together with $\mathrm{SH}$. SH performed all the growth modeling analyses. ID and HS defined the study, oversaw the data collection and data analysis, and wrote the paper together. All authors read and approved the final manuscript.

\section{Authors' information}

Not applicable.

\section{Competing interests}

The authors declare that they have no competing interests.

\section{Consent for publication}

Not applicable.

\section{Ethics approval and consent to participate}

The study was approved by the Maccabi Healthcare and Ben Gurion University IRB committees. Since all data were acquired retrospectively in an anonymized manner, there was no need to obtain consent from any of the participants.

\section{Publisher's Note}

Springer Nature remains neutral with regard to jurisdictional claims in published maps and institutional affiliations.

\section{Author details}

${ }^{1}$ Psychology Department, Ben Gurion University, Beer Sheva 84105, Israel. ${ }^{2}$ Cognitive and Brain Sciences Department, Ben Gurion University, Beer Sheva 84105, Israel. ${ }^{3}$ Child Development Center, Maccabi Health Services, Beer Sheva 84893, Israel.

Received: 25 October 2016 Accepted: 9 March 2017

Published online: 23 March 2017

\section{References}

1. Courchesne E, Redcay E, Kennedy DP. The autistic brain: birth through adulthood. Curr Opin Neurol. 2004;17:489-96.

2. Courchesne E, Pierce K, Schumann CM, Redcay E, Buckwalter JA, Kennedy DP, et al. Mapping early brain development in autism. Neuron. 2007;56:399-413.

3. Courchesne E, Karns CM, Davis HR, Ziccardi R, Carper RA, Tigue ZD, et al. Unusual brain growth patterns in early life in patients with autistic disorder An MRI study. Neurology. 2001;57:245-54.

4. Haar S, Berman S, Behrmann M, Dinstein I. Anatomical abnormalities in autism? Cortex: Cereb; 2014.

5. Bartholomeusz HH, Courchesne E, Karns CM. Relationship between head circumference and brain volume in healthy normal toddlers, children, and adults. Neuropediatrics. 2002;33:239-41.

6. Courchesne E, Carper R, Akshoomoff N. Evidence of brain overgrowth in the first year of life in autism. JAMA. 2003;290:337-44.

7. Dementieva YA, Vance DD, Donnelly SL, Elston LA, Wolpert CM, Ravan SA, et al. Accelerated head growth in early development of individuals with autism. Pediatr Neurol. 2005;32:102-8.

8. Dawson G, Munson J, Webb SJ, Nalty T, Abbott R, Toth K. Rate of head growth decelerates and symptoms worsen in the second year of life in autism. Biol Psychiatry. 2007;61:458-64.

9. Webb SJ, Nalty T, Munson J, Brock C, Abbott R, Dawson G. Rate of head circumference growth as a function of autism diagnosis and history of autistic regression. J Child Neurol. 2007;22:1182-90.

10. Elder LM, Dawson G, Toth K, Fein D, Munson J. Head circumference as an early predictor of autism symptoms in younger siblings of children with autism spectrum disorder. J Autism Dev Disord. 2008;38:1104-11.

11. Courchesne E, Mouton PR, Calhoun ME, Semendeferi K, Ahrens-Barbeau C, Hallet MJ, et al. Neuron number and size in prefrontal cortex of children with autism. JAMA. 2011;306:2001-10.

12. Hazlett HC, Poe M, Gerig G, Smith RG, Provenzale J, Ross A, et al. Magnetic resonance imaging and head circumference study of brain size in autism: birth through age 2 years. Arch Gen Psychiatry. 2005;62:1366-76.

13. Schumann CM, Bloss CS, Barnes CC, Wideman GM, Carper RA, Akshoomoff $\mathrm{N}$, et al. Longitudinal magnetic resonance imaging study of cortical development through early childhood in autism. J Neurosci. 2010;30:4419-27. 
14. Shen MD, Nordahl CW, Young GS, Wootton-Gorges SL, Lee A, Liston SE, et al. Early brain enlargement and elevated extra-axial fluid in infants who develop autism spectrum disorder. Brain. 2013;136:2825-35.

15. Courchesne E, Campbell K, Solso S. Brain growth across the life span in autism: age-specific changes in anatomical pathology. Brain Res. 2011;1380: 138-45. Elsevier B.V.

16. Hazlett HC, Gu H, Munsell BC, Kim SH, Styner M, Wolff JJ, et al. Early brain development in infants at high risk for autism spectrum disorder. Nature. 2017;542:348-51.

17. Chawarska K, Campbell D, Chen L, Shic F, Klin A, Chang J. Early generalized overgrowth in boys with autism. Arch Gen Psychiatry. 2011;68:1021-31.

18. Raznahan A, Wallace GL, Antezana L, Greenstein D, Lenroot R, Thurm A, et al. Compared to what? Early brain overgrowth in autism and the perils of population norms. Biol Psychiatry. 2013;74:563-75.

19. Zwaigenbaum L, Young GS, Stone WL, Dobkins K, Ozonoff S, Brian J, et al. Early head growth in infants at risk of autism: a baby siblings research consortium study. J Am Acad Child Adolesc Psychiatry. 2014;53:1053-62.

20. Constantino JN, Majmudar P, Bottini A, Arvin M, Virkud Y, Simons P, et al. Infant head growth in male siblings of children with and without autism spectrum disorders. J Neurodev Disord BioMed Central. 2010;2:39-46.

21. Barnard-Brak L, Sulak T, Hatz JKI. Macrocephaly in children with autism spectrum disorders. Pediatr Neurol. 2011:44:97-100.

22. Surén P, Stoltenberg C, Bresnahan M, Hirtz D, Lie KK, Lipkin WI, et al. Early growth patterns in children with autism. Epidemiology. 2013;24:660-70.

23. Gray KM, Taffe J, Sweeney DJ, Forster S, Tonge BJ. Could head circumference be used to screen for autism in young males with developmental delay? J Paediatr Child Health. 2012;48:329-34.

24. Nordahl CW, Lange N, Li DD, Barnett LA, Lee A, Buonocore MH, et al. Brain enlargement is associated with regression in preschool-age boys with autism spectrum disorders. Proc Natl Acad Sci U S A. 2011;108:20195-200.

25. Nordahl CW, Braunschweig D, losif A-M, Lee A, Rogers S, Ashwood P, et al. Maternal autoantibodies are associated with abnormal brain enlargement in a subgroup of children with autism spectrum disorder. Brain Behav Immun. 2013;30:61-5.

26. Klein S, Sharifi-Hannauer P, Martinez-Agosto JA. Macrocephaly as a clinical indicator of genetic subtypes in autism. Autism Res. 2013;6:51-6.

27. Chaste P, Klei L, Sanders SJ, Murtha MT, Hus V, Lowe JK, et al. Adjusting head circumference for covariates in autism: clinical correlates of a highly heritable continuous trait. Biol Psychiatry. 2013;74:576-84

28. Sacco R, Gabriele S, Persico AM. Head circumference and brain size in autism spectrum disorder: a systematic review and meta-analysis. Psychiatry Res. 2015;234:239-51.

29. Davidovitch M, Golan D, Vardi O, Lev D, Lerman-Sagie T. Israeli children with autism spectrum disorder are not macrocephalic. J Child Neurol. 2011;26:580-5.

30. Lord C, Risi S, Lambrecht L, Cook EH, Leventhal BL, DiLavore PC, et al. The autism diagnostic observation schedule-generic: a standard measure of social and communication deficits associated with the spectrum of autism. J Autism Dev Disord. 2000;30:205-23.

31. Lord C, Rutter M, Di Lavore P, Risi S, Gotham K, Bishop S. Autism and Diagnostic Observation Schedule, Second Edition (ADOS-2) Manual (Part I): Modules 1-4. Western Psychological Services: Torrance, CA; 2012.

32. Gotham K, Pickles A, Lord C. Standardizing ADOS scores for a measure of severity in autism spectrum disorders. J Autism Dev Disord. 2009;39:693-705

33. Fombonne E, Rogé B, Claverie J, Courty S, Frémolle J. Microcephaly and macrocephaly in autism. J Autism Dev Disord. 1999;29:113-9.

34. Lainhart JE, Piven J, Wzorek M, Landa R, Santangelo SL, Coon H, et al. Macrocephaly in children and adults with autism. J Am Acad Child Adolesc Psychiatry. 1997;36:282-90.

35. Davidovitch M, Patterson B, Gartside P. Head circumference measurements in children with autism. J Child Neurol. 1996;11:389-93.

36. Orlova KA, Crino PB. The tuberous sclerosis complex. Ann N Y Acad Sci. 2010;1184:87-105. Blackwell Publishing Inc.

37. Fombonne E. Epidemiology of pervasive developmental disorders. Pediatr Res. 2009;65:591-8. Nature Publishing Group.

38. Hertz-Picciotto I, Delwiche L. The rise in autism and the role of age at diagnosis. Epidemiology. 2009;20:84-90. NIH Public Access.

39. Croen LA, Grether JK, Hoogstrate J, Selvin S. The changing prevalence of autism in California. J Autism Dev Disord. 2002;32:207-15.

40. Teller IC, Embleton ND, Griffin IJ, van Elburg RM. Post-discharge formula feeding in preterm infants: A systematic review mapping evidence about the role of macronutrient enrichment. Clin. Nutr. 2016;35:791-801.
41. Morse NL. Benefits of docosahexaenoic acid, folic acid, vitamin D and iodine on foetal and infant brain development and function following maternal supplementation during pregnancy and lactation. Nutrients. 2012;4(7):799-840.

42. Pedersen M, Von Stedingk H, Botsivali M, Agramunt S, Alexander J, Brunborg $\mathrm{G}$, et al. Birth weight, head circumference, and prenatal exposure to acrylamide from maternal diet: the European prospective mother-child study (NewGeneris). Environ Health Perspect. 2012;120:1739-45.

43. Koubaa S, Hällström T, Brismar K, Hellström PM, Hirschberg AL. Biomarkers of nutrition and stress in pregnant women with a history of eating disorders in relation to head circumference and neurocognitive function of the offspring. BMC Pregnancy Childbirth. 2015;15:318.

44. Roak BJO, Vives L, Fu W, Egertson JD, Stanaway IB, Phelps IG, et al. Multiplex targeted sequencing identifies recurrently mutated genes in autism spectrum disorders. Science (80-). 2012;338:1619-22.

45. Gu H, Ph D, Gerig G, Elison JT, Styner M, Botteron KN, et al. Differences in white matter fiber tract development present from 6 to 24 months in infants with autism. Am J Psychiatry. 2012;169:589-600.

46. Fingher N, Dinstein I, Ben-Shachar M, Haar S, Dale AM, Eyler L, et al. Toddlers later diagnosed with autism exhibit multiple structural abnormalities in temporal corpus callosum fibers. Cortex. 2017. (in press)

47. Stoner R, Chow ML, Boyle MP, Sunkin SM, Mouton PR, Roy S, et al. Patches of disorganization in the neocortex of children with autism. N Engl J Med. 2014;370:1209-19.

48. Jeste SS, Geschwind DH. Disentangling the heterogeneity of autism spectrum disorder through genetic findings. Nat Rev Neurol. 2014;10:74-81. Nature Publishing Group, a division of Macmillan Publishers Limited. All Rights Reserved.

49. Happé F, Ronald A, Plomin R. Time to give up on a single explanation for autism. Nat Neurosci. 2006;9:1218-20.

\section{Submit your next manuscript to BioMed Central and we will help you at every step:}

- We accept pre-submission inquiries

- Our selector tool helps you to find the most relevant journal

- We provide round the clock customer support

- Convenient online submission

- Thorough peer review

- Inclusion in PubMed and all major indexing services

- Maximum visibility for your research

Submit your manuscript at www.biomedcentral.com/submit
) Biomed Central 